\title{
Derivas contemporáneas: devenir de algunos conceptos clave del arte y la estética
}

\section{Contemporary Drifts: Becoming of a few Key Concepts in Art and Aesthetics}

\author{
Circe Rodríguez \\ Universidad Nacional Autónoma de México, México \\ aurin_cs@hotmail.com
}

Resumen • Los cambios operados en la configuración y cartografía de las prácticas artísticas implicaron una revisión de las categorías, las cuales han guiado las producciones de este tipo de trabajos. Esto, a su vez, conllevó a la revisión y el cuestionamiento de estas categorías a través de las cuales se han pensado y teorizado estas actividades. El presente cuestionamiento se efectuó con la intención de evaluar y revaluar la viabilidad de sus postulados, para dar cuenta de productos artísticos elaborados dentro de un marco de referencia altamente diferenciado de aquel en el que se gestaron. El presente trabajo aborda ese devenir, con la intención de analizar las condiciones de posibilidad de los conceptos de autonomía y forma, a la luz del arte contemporáneo y principalmente de las denominadas prácticas artísticas relacionales.

Palabras clave: Arte, Estética, Autonomía, Forma, Prácticas relacionales

Abstract $•$ Changes made in the configuration and mapping of artistic practices imply a revision of the categories that guide this type of work. This leads to the revision and questioning of these categories through which these activities have been thought and theorized. The following questioning aims to evaluate and revaluate the viability of its postulates, so as to give account of certain artistic productions within a highly differentiated framework. This paper addresses this becoming to analyze the conditions of possibility of the concepts of autonomy and shape in the light of contemporary art and especially of the so-called relational art practices.

Keywords: Art, Aesthetics, Autonomy, Form, Relational Practices 
Hace poco más de un siglo que el concepto de evolución se convirtió en el motor del quehacer artístico; evolución que, entendida como innovación, tenía de base la ruptura con su propia tradición. No obstante, el ansia de novedad no era del todo novedosa, en tanto se inscribía en el ánimo de la Querelle o querella entre antiguos y modernos sucedida un par de siglos atrás.

Montada sobre una tradición de rupturas, digámoslo así, que de manera un tanto paradójica hizo de la ruptura una tradición, la praxis artística de la modernidad, como Jano, mantuvo uno de sus rostros vuelto hacia el pasado mientras el otro se encontraba fijo en el porvenir. En este sentido, es posible argumentar que para el arte de la modernidad y principalmente para el arte moderno, la historia del propio quehacer se tornó substancial en tanto fungía como punto de partida y principio de negación.

No obstante, la relación tensional con el pasado no es una condición exclusiva del arte moderno y sus vanguardias, ésta se encuentra presente en los debates que se llevan a cabo a partir de los años ochentas en el terreno artístico y prácticas artísticas que, si bien se hallan próximas a ejercicios anteriores, tienden a soslayar dicha vinculación sin tomar en cuenta el hecho de que el motor que impulsó los procesos creativos actuales fue la relación entre sus constituciones técnico-formales pretéritas y las posibilidades que esas mismas formas plantearon. Es decir, el debate en torno a las producciones artísticas contemporáneas implica la relación que estas formas establecen con su pasado, principalmente con su pasado reciente; verbigracia los gestos, las experimentaciones y formulaciones llevadas a cabo por la modernidad estilística, uno de los focos que tensa el universo artístico mientras que otro habrá de buscarse en adaptaciones y distanciamientos que realizarán manifestaciones posteriores de sus tesis centrales. Si la constitución estética, como sostiene Adorno, se forma en aquello de lo que el arte ha sido expulsado - habría que agregar, siguiendo al pensador frankfurtiano, por su propia ley de desarrollo- es principalmente por las posibilidades que se abren con ese dejar atrás.

Sin embargo, si una parte importante de la producción artística posterior a los años ochenta puede ser analizada en función de su cercanía con las manifestaciones que le precedieron, ello no implica que la práctica artística se reduzca a reproducir lenguajes pretéritos, como en su momento sugirieran algunos discursos posmodernos. Decretar la pérdida de originalidad del arte, al considerarlo meramente tautológico, es perder de vista que el llamado arte posmoderno y sus formas subsiguientes plantean propuestas y cuestionamientos con los cambios que la modernidad artística operó, articulándose en función de problemáticas heredadas por esta misma, retomando y rearticulando sus alcances y dimensiones para producir otras codificaciones, lo cual no implica que en un determinado momento las estrategias, a través de las cuales se re-codifican y re-funcionalizan los lenguajes pretéritos, no vuelvan inoperantes a las herramientas conceptuales con que pensamos estos tipos de actividad y objetualidad.

Es importante analizar cómo aquello que Adorno llamó ley de desarrollo del arte puede plantearnos la necesidad de repensar los conceptos y las categorías con que tratamos estas manifestaciones o, en su defecto, demandarnos nuevas herramientas de análisis capaces de cuestionar la existencia de semejante ley. Ejemplo del primer caso es el presente escrito, el cual tiene por objetivo problematizar dos conceptos que desde el siglo XVIII han articulado el pensamiento estético y la creación artística, cuyas condiciones de posibilidad han sido cuestionadas desde hace aproximadamente cincuenta años: autonomía y forma. Con ello, se intenta mostrar las transformaciones que dichos conceptos han 
sufrido y determinar, de tenerla, su operatividad en los discursos y prácticas artísticas, señalando, por otra parte, el hecho de que seguir empleando las categorías que la modernidad estética oficializó conlleva una serie de problemas en tanto las prácticas artísticas parecen empecinadas en mostrar su obsolescencia.

\section{PRELIMINARES}

\section{AUTONOMÍA, AUTONOMÍA ESTÉTICA Y ARTE AUTÓNOMO}

La autonomía del arte y de la estética surgió al amparo de una pretensión general: la conversión del paradigma teológico que regía el orden del ser y la existencia En este sentido, la Autonomía ${ }^{1}$, tematizada a partir del siglo xvin buscaba redefinir el papel que el hombre, entidad creada, desempeñaba en la creación, manifestando su potencialidad creadora y capacidad poyética. El reordenamiento del estatuto con que se interpretaba lo real en favor de la subjetividad, en detrimento de un paradigma teológico, perseguía menos el nuevo contenido objetivo que se hacía accesible al espíritu - la determinación de la naturaleza- que las nacientes funciones de la subjetividad y las posibilidades casi ilimitadas que esto representaba para el sujeto. Es decir, el conocimiento de la naturaleza se constituía como un reflejo de las capacidades y los alcances de la razón para reglamentar la objetividad.

Análogamente, la Autonomía, a través del auto-conocimiento humano, planteaba la libertad para discernir respecto de los fines que la propia subjetividad habría de procurarse: la libertad para disponer del contenido y cometido del sujeto como estructura universal, y por ende, del objeto. Así, la Autonomía adscrita al proyecto ilustrado, delineó el «relato» rector de la modernidad, el de la emancipación: «emancipación del destino humano de los dictados divinos, emancipación de la ignorancia y la servidumbre a través del conocimiento y la igualdad de derechos, emancipación de la explotación y la alienación por la socialización del trabajo, emancipación de la pobreza por el desarrollo técnico-industrial», empresa que a través de sus diferentes caras dejaba entrever un único thelos: la libertad universal y absolución de toda la humanidad (Lyotard, 36).

La Autonomía del yo, es decir, la independencia del pensamiento y la acción del género humano de los fundamentos teológicos que habían marcado sus principales directrices, precipitó la consolidación de las ciencias y demás disciplinas como áreas del conocimiento particulares a las cuales es posible adjudicar contenidos específicos, así como áreas de estudio relativamente bien delimitadas, entre las que cabe resaltar la Estética como disciplina filosófica, y el Arte.

La autonomía del discurso estético responde así al debilitamiento del orden que reinaba sobre lo existente y a la erección de otro en su lugar, esto es: la suplantación del orden religioso por el de la razón, la cual habría de reclamar su derecho sobre los diferentes ámbitos de la existencia: las sensaciones, la belleza y el gusto, se constituyen como objetos de análisis y disertación al interior de un discurso que exige su propia «constitución».

Con la intención de diferenciar entre estas tres formas, la autonomía como proceso general, la autonomía del arte y la de la estética, Autonomía como proceso emancipador de la humanidad se escribirá con mayúscula. 
La Estética autónoma, por tanto, se conformó como una teoría de la sensibilidad, abocada al estudio de las sensaciones, el placer, la belleza y, cada vez con mayor insistencia, del Arte. Pero sobre todo se constituyó como una reflexión del sujeto, de su sensibilidad y sobre todo, aunque en un segundo momento, de su capacidad poético-creadora. Condición que llevará a la estética cada vez más cerca del ámbito humano creador por antonomasia, el Arte. Fue en condiciones análogas a la delimitación del campo de estudio de la estética, que el Arte «alcanza» su propia autonomía; y si la autonomía estética implica la "separación», nunca del todo consumada, de los campos ético, epistemológico, metafísico a través de la delimitación de su campo de estudio, la autonomía del Arte significa su consolidación como actividad específica que logra distinguirse de las artes mecánicas, sobre las cuales priva la prosecución de una finalidad externa, erigiéndose con ello sobre la facultad creadora de los individuos, insuflada por el «espíritu humano».

Es por ello que el Arte no se limita a copiar el mundo; intenta crearlo a partir de la subjetividad. El Arte se vuelve paulatinamente un espejo del orden natural, pero no en el sentido de un mero reflejo de sus apariencias, sino en tanto actividad creadora, lo cual queda manifesto en la forma artística, al menos en aquella que, en analogía con la naturaleza, se configura como organismo vivo y autosuficiente, y que con su acción logra modificar e imprimir un sello particular a lo natural.

La forma, en su acepción romántica, es un todo «coherente y satisfecho en sí mismo, celoso de su autonomía e independencia» (Adorno, 93), que logra deslindarse de las apariencias naturales. Éstas, otrora nuevas posibilidades auto-formativas, habrían de conducirla hacia límites insospechados, es decir, el arte autónomo, al plantear sus producciones como estructuras autosuficientes, hace patente la facultad de las diferentes prácticas artísticas para trazar las directrices por las que habrían de transcurrir, situación que permitió a dichas prácticas trascender los límites del propio quehacer.

La emancipación del arte de sus vínculos míticos, mágicos y religiosos — que le permiten proponerse como fin en sí mismo-implicó una supresión de relaciones, significados y funciones que lo vinculaban a la experiencia vital. De hecho, cualquier objeto que fuera considerado una obra de arte debía ser desconectado de su contexto existencial para ser apreciado por su valor propio (Sánchez Vázquez, 275). Es importante señalar que la desconexión entre arte y existencia ordinaria, condición sine qua non de su autonomía, fue uno de los aspectos más cuestionados por la «modernidad artística radical», declarando la necesidad de sustituir la estructura autorreferencial de las producciones artísticas por manifestaciones que incidieran de manera directa en la cotidiana existencia, reactivando la potencia vital arrebatada al arte.

El proceso de emancipación de los diversos órdenes del quehacer humano, incluido por supuesto el arte, pese a haber surgido como y a partir de una postura crítica y revolucionaria del papel que desempeñaba el ser humano —en el mundo y en el proceso del acto creador- aparecía ante los ojos de los artistas de vanguardia como una entelequia impotente frente a la existencia, situación que habría de producir una aporía en el seno del arte moderno: la condición que permite transformar tanto la noción de arte como la praxis artística, esto es, la autonomía atacada para que dichas transformaciones pudieran consumarse.

En este sentido, uno de los argumentos que se opuso fervientemente a la noción de obra autónoma, fue aquel que criticó la distancia entre obra y existencia ordinaria, por tanto, cualquier pretensión de pureza que ésta pudiera enarbolar, como se deriva de los 
supuestos constructivistas - aunque en un extremo opuesto-y los dadaístas. A decir de estos movimientos, las prácticas artísticas debían incidir de manera directa en la cotidianidad, puesto que es por su desenvolvimiento en el mundo práctico que pueden liberar su fuerza crítica y revolucionaria.

No obstante, la posibilidad de incidir sobre las condiciones de existencia requiere que las formas artísticas posean un cierto grado de independencia, es decir, si el arte se transforma en una herramienta subsidiaria del diseño o un apéndice de la publicidad, como parecería indicar su adaptación a la industria de la cultura, renuncia a su fuerza transformadora. Esta condición parecería indicar que las producciones artísticas requieren o, si se prefiere, presuponen autonomía, aunque sea relativa. Relativización que con las vanguardias se hizo cada vez más patente. Dada la relación entre autonomía y forma aquí insinuada, es posible adelantar que el ánimo reformador de las vanguardias artísticas no dejó incólume a la forma.

\section{FORMA}

Uno de los conceptos definitorios en la producción material y discursiva de lo que hoy por hoy denominamos estética y arte es la forma, principalmente cuando dichos dominios se afirman autónomos. Es decir, el hecho de que la postulación del arte como disciplina autónoma se sustente sobre la libertad que éste posee para auto-conformarse, prefigura que la autonomía del arte se conciba como autonomía de la forma artística (Pérez Carreño, 256). Con esto, se postuló la capacidad de darse su propia ley formal; condición que finalmente motivó a que fuese la forma lo que liderara la vanguardia en el terreno artístico.

La relevancia de la forma llegó a ser tal que se generó una especie de equivalencia entre obra y forma, de manera que para los pensamientos románticos fieles al formalismo de Kant y Schiller, así como para muchos de sus sucesores, el órgano de la reflexión artística era la Forma (Marchán Fiz, La estética en la cultura moderna, 93). No obstante, la creciente adhesión o recurrencia al formalismo no se trabajaba con un concepto rigurosamente delimitado, por el contrario, las diferentes acepciones del término solían entremezclarse ${ }^{2}$.

La forma ha sido pensada a partir de dos principios básicamente: como armonía, en concordancia con las estéticas de corte clasicista, y como correspondencia o necesidad entre las partes consigo mismas y entre las partes y el todo; línea de pensamiento que corre directamente hacia la concepción romántica de la obra como un organismo vivo, autodeterminado, coherente en sí mismo y ordenado a partir de una necesidad interna ${ }^{3}$.

Cabe señalar que ambas posturas suponen una relación unitaria entre forma y apariencia en tanto la representación artística que se consideraba más lograda era aquella

2 Es importante recalcar que en el análisis del arte se conectan diversos discursos cuya delimitación no es fácil de llevar a cabo; discursos que tienen que ver con la propia producción artística, con la estética, la historia del arte y más recientemente con la teoría del arte, por lo cual no sólo existe más de una posibilidad de interpretar la relación entre autonomía y forma, la mayoría de las veces los discursos tienden a relacionarse íntimamente y tienden incluso a confundirse.

3 Para las corrientes formalistas más apegadas al ideario romántico, esta última acepción servía como modelo de orden para la existencia, dado que frente a la fragmentariedad y dispersión del mundo, la forma artística gozaba de unidad y coherencia interna. 
en la que se alcanza el mayor equilibrio entre la forma y su apariencia, considerada en términos de armonía interna y coherencia entre las partes. Así, a la noción de forma se le aparejan términos que cuentan con una larga y a veces problemática historia para el pensamiento estético ${ }^{4}$, como son la belleza, la perfección, la proporción o la armonía, entendida esta última como conciliación, y por qué no, sometimiento, entre las partes.

La indeterminación en el empleo del concepto forma hacía necesario repensar la muchas veces presupuesta equivalencia entre forma y obra, así como los problemas que de ella se derivan. Es decir, la identificación de la obra con su aspecto formal hace evidente la antigua y conflictiva distinción entre forma y contenido como condiciones no sólo disociadas entre sí, sino antepuestas la una con la otra, y en lo cual o la forma funge como medio para la expresión de un contenido preexistente o el contenido se torna una condición subsidiaria de la organización visual, auditiva, etcétera.

Otra de las dificultades con las que se topa tanto la obra de arte como la forma es su vinculación a la apariencia, lo cual pone sobre la mesa el antiquísimo problema filosófico entre apariencia y realidad. En relación a este problema, se han planteado al menos dos cuestiones problemáticas: el tema de la representación, y la distinción entre copia y realidad; verdad y ficción.

Cabe señalar que la necesidad de revisar e imputar las acepciones en uso de la forma surgió de la práctica artística en un movimiento análogo al postulado en torno a la noción de autonomía. Es decir, la vinculación entre autonomía y forma hizo que, al interior de las prácticas artísticas, cualquier crítica o adhesión a la autonomía tuviera que reflejarse en la forma.

\section{CUESTIONAMIENTOS}

Al interior de los movimientos de vanguardia encontramos diversas posturas frente al problema de la autonomía artística, las cuales suelen agruparse en dos tendencias: la adhesión a este postulado o su negación radical. Como hemos señalado, ambas posturas repercuten directamente en el aspecto formal. Por ejemplo, vanguardias tempranas como el Cubismo y el Expresionismo priorizaban la independencia del arte sobre cualquier intención mimética o representativa - mímesis en su sentido de copia o igualación de la empiria-; la obra habría de convertirse en un mundo puro, un universo autónomo con leyes propias que se autoproponía un contenido nuevo y original (Mario De Micheli, 98). Este planteamiento, que posteriormente sería adoptado por algunos abstraccionismos, implicaba una separación de la forma estética de la realidad social o, en su defecto, la limitación de lo narrativo en aras de la investigación. Para estos artistas, el compromiso social se supeditaba a la forma y a partir de ella emitía sus resonancias, de tal manera que la crítica, de llevarse a cabo, se hacía a través de las estructuras de la propia obra (Jesús Fernández, 150).

Por otra parte, se encuentran aquellas tendencias que, en pos de una crítica severa a la civilización que les vio nacer o por un compromiso político, buscaron liberar al arte de

Estética aparece aquí con minúsculas dado que no hace referencia a la acepción moderna del término, sino a la historia del pensamiento que sobre el arte y la sensibilidad se desarrolló desde la época clásica. 
sus viejos ropajes, Dadá, Surrealismo, Suprematismo ruso y Bauhaus, entre otros; movimientos que abogaban por la superación del arte burgués en interés de algo más: un arte público, la estetización de la vida, la liberación de las fuerzas creativas de los individuos, la afirmación de la existencia, etcétera, en resumen, la abolición de viejas categorías y de las instituciones que se levantaron sobre este quehacer.

Los proyectos que se proclamaron opuestos entre sí convergen en un mismo punto: transformar el arte al modificar la forma artística, lo cual sólo sería posible partiendo del principio que se intentaba negar: la autonomía. Es decir, toda posibilidad de subvertir el carácter de la obra como una construcción autosuficiente e independiente de la praxis vital que se llevaba a cabo gracias a la posibilidad de modificación que el carácter autónomo del arte había otorgado al mismo. Ahora bien, la existencia de un punto de convergencia tan relevante, la forma, explica la aparente contradicción que algunos artistas de las vanguardias manifiestan y que podría interpretarse como una contravención a la norma vigente, la adhesión o repudio del sintagma autonomía artística.

Es posible encontrar un ejemplo claro de dicha contradicción en tendencias que manifiestan un fuerte compromiso político y un claro afán por reintegrar el arte a la vida a partir de un lenguaje plástico que se alimente de problemas inherentes a la actividad pictórica o escultórica. La síntesis del volumen o el plano dirigían las investigaciones visuales que, por su parte, se desligaron de cualquier referente externo: grupos como el Constructivismo, De Stijl o la propia Bauhaus, que tenían como centro de sus investigaciones la interacción de las estructuras formales, reducidas a su mínima expresión, con el plano y el color. Las tensiones de la imagen y su composición pretendían, como en su momento solicitara Tatlin, unir las formas "puramente artísticas» con funciones utilitarias, pero la sola mención de algo "puramente artístico", viniendo de tendencias que pretenden dejar atrás la pureza, evidencia las contradicciones presentes en las prácticas artísticas de la época.

Ya fuese desde el postulado del arte por el arte o del arte como expresión de la existencia, cambios, transformaciones, y mutaciones de la forma - llevada a cabo por las vanguardias-, tanto la forma artística como el propio concepto de arte y de obra artística fueron llevados al límite a través del hecho de subvertir su autonomía, cuestionar sus códigos visuales, trasgredir sus condiciones técnicas y formales, e incluso alterar sus formas de denominación. De esta manera, se cuestionó el pensamiento estético y la relación que éste estableció, un par de siglos antes, con las formas artísticas.

Al pensamiento en torno al arte le fue imperioso revisar los conceptos a través de los cuales había abordado la actividad artística y sus producciones. En el ámbito de la estética, encontramos reflexiones que ponen en cuestión los supuestos teóricos vigentes, tales como el carácter orgánico de la forma, la forma artística como producto del genio, su participación en los sistemas filosóficos, y por tanto el carácter metafórico de sistema atribuido a la misma, el carácter privilegiado de la forma artística en relación con la naturaleza, la belleza y el placer como categorías centrales, entre otras.

Para Adorno, por ejemplo, la forma es el lugar de mediación donde se reúnen los componentes materiales de la obra con el contenido de todos los momentos de la lógica artística, así: «la forma estética es la organización objetiva de cada uno de los elementos que se manifiestan en el interior de una obra de arte como algo sugerente y concorde. Es la síntesis no violenta de lo disperso» (191). Según este filósofo, la obra no puede identificarse con su forma ya que eso implicaría elevarla al rango de totalidad. Es decir, hacer 
de ella el elemento que subsume o supedite al grueso de las determinaciones artísticas, le haría recaer en una posición idealista. Si bien para Adorno la forma es entendida como una unidad, ésta no implica la subsunción de los diversos componentes de la obra; ella funge como un elemento de cohesión, de vinculación entre las diversas tensiones que la estructuran. Es por ello que la forma no es una mera apariencia, el aparecer ante la sensibilidad, ella depende del contenido, lejos de su tradicional oposición con la forma. En el pensamiento adorniano estos componentes se encuentran mediados, de manera que la forma determina o influye al contenido si y sólo si es modificada por aquél; condición que, cabe señalar, fue una constante en los movimientos de vanguardia.

La obra, entonces, puede pensarse como una construcción cuyos elementos son organizados a partir de diferentes supuestos compositivos que requieren de medios técnicos para su articulación, y donde la forma se asume como una organización de los elementos que la componen como principio de unidad, no de uniformidad o unificación.

Por otra parte, si bien las vanguardias sentaron la bases para la crítica del universo del arte - de su producción, de sus productos, sus discursos y los discursos que se generan en torno a él一, ésta se radicalizó desde los años sesenta del siglo pasado, haciéndose cada vez más recurrentes los cuestionamientos en torno a los lenguajes artísticos y sus categorías, a las características sintáctico-formales de la obra e incluso a su materialidad y constitución objetual. Siguiendo esta lógica, se han puesto en cuestión aquellas nociones que pretenden generalizar las diferentes propuestas bajo estructuras más o menos definidas, como ocurre con las nociones de estilo y movimiento, o los términos y discursos que buscan universalizar las propuestas artísticas y sus variaciones formales. Incluso la categoría Arte, pensada o entendida como una serie de actividades que poseen características en común como su apelación al placer y a la belleza, su carácter contemplativo y universal, han sido puestas en entredicho. No sólo los conceptos presuntamente intemporales heredados de la estética clasicista son denostados, igual suerte corren las visiones progresistas que piensan el arte en función de su permanente movilidad y constante progresión.

Es decir, con base en las construcciones artísticas vanguardistas y pos vanguardistas, en sus experimentos e inflexiones a la concepción moderna del arte, y en el rebuscamiento de las formas y procedimientos artísticos que rebasan todos los modelos pretéritos, ha sido imperioso abandonar las categorías heredadas tanto del clasicismo como de la tradición sistemático-romántica, las cuales fracasaron debido al empleo metódico de hipóstasis y abstracciones genéricas (Marchàn Fiz, Del arte objetual al arte de concepto, 12). Por esta razón, para explicar un panorama cada vez más fragmentario y polivalente, se recurre a las poéticas, esto es, a reflexiones que se articulan en torno a los objetos y fenómenos artísticos particulares, por lo cual la reflexión «tiene como premisa el conocimiento histórico concreto de las obras estudiadas»(Ibíd.).

Una vez desechadas las pretensiones de universalidad —así como el paradigma que señala que las obras artísticas son objetos cuya unicidad y originalidad los destina a la contemplación desinteresada y placentera-, los cuestionamientos que las prácticas artísticas y las denominadas formas relacionales plantean al pensamiento son copiosas; interrogantes que cuestionan la existencia de pautas vinculantes que unifican la diversidad de propuestas, la posibilidad de seguir empleando un término genérico que agrupe no sólo tendencias variadas, sino que abrace manifestaciones que parecerían no tener demasiado en común, como un video y una sonata. Interrogantes que, sin lugar a dudas, plantean un problema mayor: la posibilidad de seguir pensando el Arte y sobre todo, 
cómo ha de ser pensado: ¿producciones, artefactos, procesos o redes de acciones, relaciones y propuestas que interactúan con los individuos y su realidad en formas más o menos determinadas? En otras palabras, se plantea la pregunta por cómo los discursos sobre el arte contemporáneo se construyen, y en qué medida dicha construcción está determinada por su pasado reciente.

Con antelación, se hizo hincapié en la importancia que la Autonomía, y con ella la forma, poseía para las manifestaciones de vanguardia y para el pensamiento estético de la modernidad. Desde esta situación y por las severas críticas imputadas a este principio - la Autonomía-, es que me he cuestionado sobre la suerte que estos dos términos, otrora fundamentales, han corrido al seno de las prácticas artísticas contemporáneas y por supuesto del pensamiento abocado a reflexionarlas. Es importante señalar que dicho cuestionamiento no está guiado por el afán de «revivir viejos fantasmas» o por la necesidad de aferrarse a categorías que podrían parecer anticuadas e inoperantes; obedece a un interés por indagar cómo operan, de hacerlo, estas categorías en un marco de referencia altamente diferenciado del que les dio vida, lo cual, por otro lado, evidencia las dificultades que se experimentan al tratar de interpretar los problemas del arte contemporáneo con estéticas que se relacionan privilegiadamente con formas, digámoslo así, modernas.

Ahora bien, hablar de arte contemporáneo o de las producciones artísticas visuales, para ser más exactos, es de por sí problemático dada la considerable multiplicidad de propuestas que se agrupan bajo esta noción, entre las cuales se pueden citar: las nuevas tendencias icónicas o representativas, los anti-informalismos, los planteamientos que desbordan el estatuto existencial de la obra y las nociones tradicionales del objeto artístico, vertiente de la cual sobresalen aquellas formulaciones que persiguen un cometido político al «filtrarse» en la existencia cotidiana para reordenar los códigos y gestos que constituyen (y se constituyen en) relaciones sociales. Estas últimas son quizá las que mayor problematicidad ofrecen para el pensamiento estético y para las concepciones tradicionales del arte, por tanto, son el eje del siguiente análisis.

\section{AUTONOMÍA Y FORMA EN LAS PRÁCTICAS ARTÍSTICAS CONTEMPORÁNEAS}

\section{PRÁCTICAS RELACIONALES}

Para el arte moderno la actividad artística dejó de ser considerada creación ex nibilo y el artista, un demiurgo que crea a voluntad; hacer arte fue juzgado como podemos observar en Benjamin y Adorno, la acción de un individuo que trabaja con un material performado históricamente y por tanto, inmerso en una red de significados sociales, económicos, etc. Un número importante de prácticas artísticas generadas a partir de los años ochentas pretenden hacer de esta actividad una membrana porosa que se construye y destruye a partir de los intercambios que ella misma propicia y potencia.

Más que la posibilidad de apartarse de la representación, el arte moderno legó a sus sucesores la posibilidad de distanciarse de la esfera subjetiva de la experiencia estética, del proceso intuitivo de creación a partir de una experiencia subjetiva única, así como de las dimensiones reflexivas ligadas a este proceso creativo (Subirats, 40). El debilitamiento 
del sujeto en tanto forma unitaria — el cual se erigía como el elemento regulador y factor de cohesión de los discursos y por tanto de sus pretensiones de verdad- generó que el arte se abocara a reflexionar ya no la constitución de la subjetividad ni sus condiciones de posibilidad, sino que las formas por las cuales se estructuran individualidades formando «comunidades», lo cual, para la filosofía del lenguaje, son comunidades lingüísticas o comunicativas.

La subjetividad era un presupuesto elemental en la construcción de la forma moderna, en tanto era el sujeto quien a partir de la escucha del material producía formas altamente especializadas, de manera que el objeto artístico era resultado de la mediación entre la racionalidad no instrumental y la materia históricamente condicionada. Para prácticas artísticas contemporáneas, como las relacionales, dicha figura es desestimada por completo; allí poco importa la visión del arte como manifestación del coto privado del autor y por tanto como resultado, irrepetible, de la experiencia e ideología de un yo único (Jameson, 171). La noción de autor se considera una «estrategia transversal» que comunica los diversos estratos que conforman las operaciones creativas (Bourriaud, 117). El pináculo de la subjetividad desde la ilustración, el artista, sirve de interconexión entre los sectores que convergen en el momento artístico. Sin embargo, la relación no es entre el mundo y su sustrato trascendente - dupla sensible inteligible por poner un ejemplo-, sino entre «realidades» o experiencias que se entretejen.

Las obras se convierten en situaciones públicas cuya activación poyética o formulación simbólica corre a cargo del participante. Este tipo de propuestas llevan al límite el proceso iniciado por las obras abiertas plantadas por Eco, exigiendo al concurrente la mayor participación y compromiso que se haya planteado antes en el arte, en tanto el espectador debe trabajar para producir el sentido a partir de objetos cada vez más livianos; no sentir nada es no trabajar lo suficiente (Bourriaud, 28).

Por otra parte, en el terreno de las artes visuales - prácticas artísticas que experimentaron una mayor diversificación y vieron considerablemente modificados sus procesos y estructuras internas- el hacer se alejó de los problemas que el purismo estético planteaba para explorar zonas limítrofes. Performances, happenings y apropiaciones espaciales, entre otros, mostraban el interés de los productores por traspasar los contornos del objeto o la tela, asomándose a la ventana del mundo común y comunitario. En este sentido, el objeto - o artefacto material— dejó de ser la fuerza centrípeta del quehacer artístico, a través de él se despacharon diversas categorías con las que se solía delimitar el arte, así como problemas considerados propios del «oficio».

Los objetos son meras etapas de transición en el desarrollo artístico. De hecho, la obra se constituye como una forma procesual, un trabajo que ha de ser completado por aquel que «cierra» el círculo. Así, la creación y el uso de los objetos están condicionados por los encuentros o contextos en que éstos sean utilizados, la función del objeto podría nunca ser la misma o, por su parte, el desplazamiento operado sobre algún artefacto proveniente de la vida cotidiana ser único e irrepetible.

En relación con las categorías artísticas de autonomía y forma, Bourriaud señala que la estética relacional es una teoría de la forma, en donde por forma ha de entenderse una «unidad coherente, una estructura (entidad autónoma de dependencias internas) que presenta las características de un mundo» (19). Cabe señalar dos cosas, en primer lugar el recurso a la forma y en segundo lugar, su carácter de entidad autónoma. 
La forma para Bourriaud se concibe como punto de confluencia de dos o más «elementos paralelos». Ella hace coincidir realidades que al ponerse en contacto crean un "mundo"; la forma sería entonces lo que se crea al coexistir estas potencias. Sin embargo, no es posible proponer síntesis alguna, en tanto la obra no se constituye a través de opuestos ni duplas dialécticas, ella es un «encuentro 〈duradero〉 de heterogéneos», de experiencias, planos, manchas, colores, etcétera.

Por ello, a diferencia de sus antecesoras, las formas relacionales deben pensarse menos como un objeto o artefacto cuya existencia tendría que aferrarse contra la destrucción temporal, como estrategias de uso y resignificación de los objetos y las relaciones. Su pervivencia o supervivencia no se da — aunque puede hacerlo, desde su condición materialsino por el encuentro que ella produce y los sentidos que esto crea. Por tanto, si la forma, como sostiene Bourriaud, plantea posibilidades de vida y modelos de mundo viables, esto es posible en la medida en que hace coincidir elementos hasta entonces distanciados para que su coexistencia proponga nuevas situaciones o problematice las ya existentes.

Es importante señalar que la forma así planteada dista mucho del concepto de obra como unidad concebida por los románticos. La unidad sugerida por el crítico francés se refiere a la relación que establecen los componentes que conforman o forman la obra, entendida como un conjunto cuyo sentido, dirá, es plantear posibilidades de «vidas nuevas». Se podría preguntar qué hace diferente a este tipo de obras de propuestas anteriores que comunican de igual manera elementos inconexos, distantes, y cuya puesta en escena conjunta plantea lecturas alternas a situaciones ya conocidas, o en su defecto, genera situaciones "novedosas» ante problemáticas ya existentes, las cuales establecen la posibilidad de acercar realidades heterogéneas creando con ellas un "acontecimiento", algo que fractura el orden de sentido establecido y con ello da pie, forma o genera, uno nuevo. Podríamos decir semejante a lo que Benjamin llamara una imagen profana.

A diferencia de la propuesta benjaminiana o del ánimo duchamptiano, estas obras pretenden disminuir al mínimo la violencia que la instauración de una «realidad alterna», o al menos que una lectura diferente de la misma trae consigo; el mundo que toma por modelo se conforma a través del consenso, no así de la confrontación, su cometido no es el choque, sino el diálogo, el cual se forma y conforma sobre la base de interacciones humanas basadas en una comunidad que se considera originariamente lingüística. No obstante, Bourriaud pretende «saltar» por encima de la «fuerza revolucionaria vanguardista", sin tomar en cuenta que todo acto de reapropiación es al mismo tiempo un acto de fuerza contra la cosa, su sentido o significado instituido.

Aquí la forma no existe si no es a través del otro, porque es el otro quien posibilita su existencia y construcción, en esto consiste su «dialogicidad». A diferencia de sus antecesoras, la estética relacional propone como eje el diálogo, la intersubjetividad y el carácter interactivo. Ello hace que la forma no pueda limitarse al objeto material, el cual, entendido como forma material, pierde su primacía al poder ser desechado o remplazado sin la menor objeción por parte del «autor». De hecho, dicho objeto bien puede perder su condición "artística» en tanto cesa su manipulación: «El arte actual muestra que sólo hay forma en el encuentro, en la relación dinámica que mantiene una propuesta artística con otras formaciones artísticas o no» (Bourriaud, 19). De esta manera, la forma no puede circunscribirse a un sistema compositivo o de relaciones entre las partes, como ocurre en creaciones de otros órdenes, entiéndase las comprendidas en la estética de lo sublime, las cuales conservan rasgos del concepto moderno de obra artística. 
Es claro cómo las lecturas tradicionales de la forma que ponen el acento en su constitución y desarrollo técnico-formal son insuficientes para abrigar las prácticas relacionales; para quienes la forma no se constituye, al menos no necesariamente, a partir de líneas compositivas, fuerzas y tensiones, sino de situaciones y experiencias, situación diametralmente opuesta a una parte importante de la producción de vanguardia:

La esencia de la práctica artística residiría así en la invención de relaciones entre sujetos; cada obra de arte en particular sería la propuesta para habitar un mundo en común y el trabajo de cada artista, un haz de relaciones con el mundo, que generaría a su vez otras relaciones y así sucesivamente hasta el infinito (Bourriaud, 22).

Esta noción de obra es descrita por Bourriaud como una entidad autónoma de dependencias internas; aseveración que no deja de ser problemática en tanto la autonomía adscrita a las obras pretéritas poco tiene que ver con las formas relacionales a decir de lo aquí expuesto. Ellas no intentan poner en relieve la facultad poiética de los individuos o construir espacios simbólicos privados, ni postular la capacidad del arte para darse su propia ley. Luego entonces, ¿cómo podría o debería entenderse aquí la Autonomía? Por otro lado, no es del todo claro en qué sentido una invitación a cenar, una llamada por teléfono, una caja de zapatos o la proyección de imágenes sobre edificios, pueden cumplir con la condición de ser una entidad autónoma de dependencias internas.

Podría argumentarse que su carácter autónomo radica en la delimitación que como obra artística pueda hacerse de ella, pero no en el sentido de una forma cerrada de existencia independiente o un "sensible heterogéneo", sino en tanto la posibilidad de reconocer que eso que se presencia pertenece a una «esfera particular de la existencia sensible», que a su vez se erige como una propuesta de tipo artístico.

Si la condición autónoma de la forma radicara en la distinción real o adjudicada de la propuesta u objeto, ¿cómo sería posible reconocer los diversos elementos que participan en ese rubro de la experiencia? $\mathrm{O}$ en su defecto, ¿quién avalaría dicha distinción? La primera interrogante implica una estética normativa que prescribe cuáles son las características, ya deseables y necesarias, que un objeto o propuesta deben poseer para ser reconocidos como tales. Postura que adolece de sustento en tanto, al menos en nuestra contemporaneidad, no es posible dictar normas que regulen la apariencia o constitución de las propuestas artísticas.

En lo que a la segunda cuestión se refiere, habría que decir o decidir quién posibilita su pertenencia a dicho coto: ¿los teóricos del arte, los críticos, los museos y galerías, los corredores y comisarios; el individuo que las propone?, o en su defecto, ¿aquel que a sabiendas de que lo que ve puede ser un objeto sin ninguna cualidad diferente al que le es dado conseguir en el supermercado, acepta la propuesta estética cerrando el círculo del sentido? Esta pregunta es sumamente compleja en tanto en ella se cruzan una serie de líneas de fuerza que van desde cómo se concibe la subjetividad y cuál es el estatuto que se le otorga en la actividad artística, hasta la conformación de los discursos artísticos y sus estructuras de saber y poder, por decirlo con Foucault.

Me parece que, al menos como plantea la estética relacional, un arte que se concibe a sí mismo comunitario, debería constituirse en base al acuerdo entre los diversos elementos que lo componen, entendiendo como elementos la comunidad o comunidades que de él participan, las cuales, en determinado momento, podrían considerarse a su vez elementos de la forma. La propuesta artística parecería o aparecería como un mero gesto 
que provoca la complicidad entre las partes. Sin embargo, esta interpretación no deja de ser problemática, en tanto parecería condenar a la obsolescencia nuestro concepto de obra en uso.

En la condición de entidad autónoma sería posible, por ejemplo, un acuerdo intersubjetivo a través del cual se acepta una «forma» como «forma artística», basándose en ciertas prácticas más o menos identificadas que cuenten con una historia y formas institucionalizadas relativamente específicas. Dicha especificidad sería, por tanto, proponer maneras y acciones determinadas para relacionarnos con el mundo e interpretar sus signos; plantear una manera particular de habitar el espacio y el tiempo ${ }^{5}$. Esto es una postura cercana a lo que Ranciére denomina régimen de identificación del arte, esto es, la relación de «determinadas prácticas con formas de visibilidad y modos de inteligibilidad específicos», en los cuales, como ya mencionamos, confluyen la historicidad del fenómeno en cuestión, la institución artística e incluso la idea de que en ese momento la caracterización prevalece sobre el sujeto en tanto productor de artefactos y experiencias estéticas; "consumidor», receptor y/o coautor de las mismas, entre otras condiciones.

Siguiendo a Ranciére diremos que no nos es posible hablar del arte sin referirnos a un régimen de percepción y de pensamiento que permita distinguir sus formas como formas comunes y por qué no, como formas artísticas (Ranciére, 29). Si bien la estética relacional no plantea la existencia de objetos o formas específicas para poder adjudicar los resabios de una autonomía otrora reinante, tampoco diluye la obra en el mar de la existencia cotidiana. Existe una membrana de contención presente en la definición misma de la forma, una membrana tan flexible que, como argumenta Ranciére, permite el tránsito constante, ya cotidiano, desde el mundo del arte al de las mercancías ${ }^{6}$ y desde las mercancías al mundo del arte: «La autonomía estética no es esa autonomía del «hacer» artístico que la modernidad ha oficiado. Se trata de la autonomía de una forma de experiencia sensible. Y es esa experiencia la que construye el germen de una nueva humanidad» (Ibíd.). Pues bien, hemos dicho que para Bourriaud, la forma se crea y recrea a partir del que la observa, la interpreta y hace suya, tanto como de la comunidad hacia la cual se dirige y de la cual se alimenta:

No existen formas en la naturaleza, en estado salvaje, ya que es nuestra mirada la que las crea, recortándolas en el espesor de lo visible. Las fronteras se desarrollan una a partir de otras. ... (Así) la forma toma consistencia, y adquiere una existencia real, sólo cuando pone en juego las interacciones humanas, la forma de una obra de arte nace de una negociación con lo inteligible (Bourriaud, 22).

Esto es, si la forma sólo puede surgir de y en lo comunitario, su tan citada condición de entidad autónoma únicamente podría ser concebida como autonomía de la experiencia que ella posibilita. La forma al ejercer como vínculo entre individuos propone experiencias, y la Autonomía de dichas experiencias sería la libertad que ella propicia para habitar el mundo y crear otro tipo de relaciones entre las personas. De alguna manera, la Autonomía así planteada sería ese espacio «único» que se abre a partir de la propuesta artística en el seno de la «dimensión relacional de la existencia» (Ibíd.). De ser mi argumentación adecuada, poco o nada queda de los restos de la Autonomía oficiada por la

\footnotetext{
El problema aquí sería delimitar en qué consiste esa determinada manera, es decir, cuáles serían las características de dicha experiencia.

$6 \quad$ Posibilidad que en el arte kitsch de los años ochentas y noventas encontrara su cúspide.
} 
modernidad. Sin embargo, evocando nuevamente al crítico francés, podríamos señalar que cuando la discusión estética evoluciona, el estatuto de la forma evoluciona con ella y en ella, y aparentemente podríamos añadir el de la Autonomía y la obra también.

\section{REFERENCIAS}

Adorno, Theodor. Teoría estética. Trad. Fernando Riaza. Taurus: Madrid, 1971. Medio impreso.

Bourriaud, Nicolas. Estética relacional. Trad. Cecilia Becerro y Sergio Delgado. Ed. Adriana Hidalgo. Buenos Aires: 2006. Medio impreso.

De Micheli, Mario. Las vanguardias artísticas del siglo XX. Trad. Ángel Sánchez Gijón. Alianza: Madrid, 1966. Medio impreso.

Fernández, Jesús. Th.W. Adorno: Mimesis y Racionalidad. Materiales para una estética negativa. Diputación de Valencia, Institución Alfons el Magnànim: Valencia, 2004. Medio impreso.

Marchán, Simón. Del arte objetual al arte de concepto. Akal: Madrid, 2009. Medio impreso.

. La estética en la cultura moderna. Alianza: Madrid, 2000. Medio impreso.

Paz, Octavio. «Los privilegios de la vista». Obras completas. VI. FCE: México, 1994. Medio impreso.

Ranciére, Jacques. Sobre políticas estéticas. Trad. Manuel Arranz. Publicaciones de la Universidad Autónoma de Barcelona: España, 2005. Medio impreso.

Rolnik, Suely. «¿El arte cura?». Quaderns portàtils: MACB. Sitio web.

Sánchez, Adolfo. «Socialización de la creación o muerte del arte». Cuestiones estéticas y artísticas contemporáneas. FCE: México, 1996. Medio impreso.

Subirats, Eduardo. Culturas Virtuales. Ediciones Coyoacán: México, 2001. Medio impreso.

Vozal, Valeriano, ed. Historia de las ideas estéticas y de las teorías artísticas contemporáneas, II, VI. Visor: Madrid, 2000. Medio impreso.

Recepción: Octubre 2011

Aceptación: Marzo 2012 